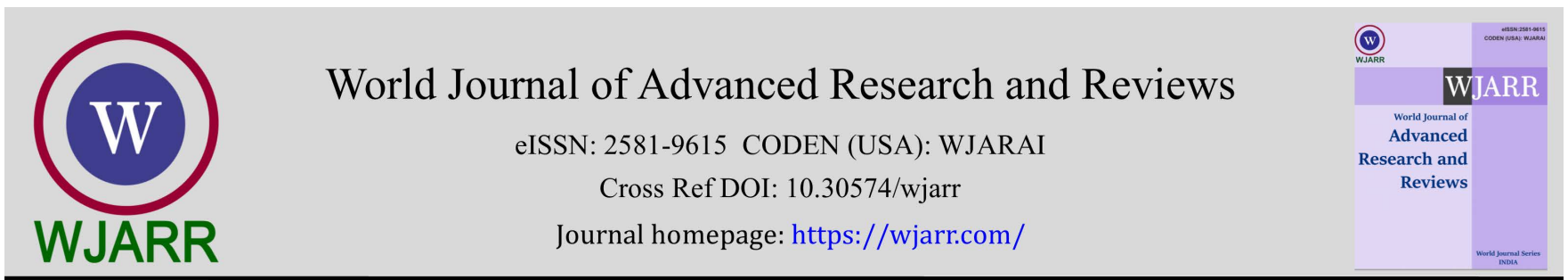

(RESEARCH ARTICLE)

\title{
Neurocognitive deficits among adult road traffic accident victims at the University Teaching Hospital, Lusaka, Zambia
}

\author{
Claudius Chisha Mwenya, Anatolii Tsarkov *, Petro Petlovanyi and Ravi Paul \\ Department of Psychiatry, School of Medicine, University of Zambia (UNZA)
}

World Journal of Advanced Research and Reviews, 2021, 11(03), 436-452

Publication history: Received on 23 August 2021; revised on 26 September 2021; accepted on 28 September 2021

Article DOI: https://doi.org/10.30574/wjarr.2021.11.3.0483

\begin{abstract}
Introduction: Road traffic accidents (RTAs) are of growing public health importance worldwide contributing significantly to the global disease burden thus public health experts worldwide concede that there is a global epidemic of RTAs. Exposure to RTAs may be associated with changes in brain functioning and cognitive performance.
\end{abstract}

Objective: This study sought to contribute to the understanding of the neurocognitive deficits among adult victims of RTAs.

Methodology: It is a cross-sectional study (descriptive in nature). Cognitive profiles of the affected participants were assessed by selected tests from the International Neurobehavioral test battery. The quality of life was assessed by application of the World Health Organisation Quality of Life (WHOQOL) questionnaire. The primary data obtained was analyzed using descriptive and inferential statistics using SPSS.

Results: Twenty-seven (27) RTA victims out of Thirty (30) had executive functioning impairment with a Domain Deficit Score (DDS) of $\geq 0.5$ and all the RTA victims in the study had speed of information processing impairment with a Domain Deficit Score (DDS) of $\geq 0.5$. There was no significant statistical gender difference in neurocognitive functioning (Executive functioning $\mathrm{F}=0.85, \mathrm{P}=0.36$; Speed of information processing $\mathrm{F}=0.98, \mathrm{P}=0.33$ ). Compromised quality of life among adult victims of road traffic accidents was confirmed $(\mathrm{P}=0.005)$.

Conclusion: This study shows an association between RTA and neurocognitive functioning in adult victims. Findings of this study show the presence of neuropsychological impairments in the two domains assessed (executive functioning and speed of information processing). The study indicates that RTA significantly compromises the quality of life.

Keywords: Neuropsychology; Road Traffic Accident; RTA; Neurocognitive functioning; Quality of life; Executive functioning; Speed of information processing

\section{Introduction}

Developing countries, sub-Saharan African countries in particular, have been known to face double burden of diseases [1]. Poor governance and corrupt practices in most sub-Saharan African countries had led to poor construction and maintenance of social amenities such as roads. There have been many cases of road traffic accidents (RTAs) resulting from low construction standards and poor road maintenance [2]. Avoidable road traffic accidents have continued to add to morbidity and mortality in most sub-Saharan African countries. The issue of road traffic accidents is reaching an alarming state in Zambia. According to the Government report (2017), road traffic accidents have become one of the most common causes of death and injuries in Zambia [3]. In the end of 2016, a total of 32350 road traffic accidents were

\footnotetext{
* Corresponding author: Anatolii Tsarkov

Department of Psychiatry, School of Medicine, University of Zambia (UNZA).
}

Copyright $@ 2021$ Author(s) retain the copyright of this article. This article is published under the terms of the Creative Commons Attribution Liscense 4.0 
recorded compared to 33672 in 2015 representing a 4\% reduction in road traffic accidents. Even with this reduction the figures are still too high and poses a challenge to attaining the vision of reducing road traffic accidents. Although the number of road traffic accidents reduced in 2016, the number of fatalities increased from 2113 in 2015 to 2206 in 2016 representing an increase of $4 \%$.

The records reviewed at the Emergency Department of the University Teaching Hospital (Lusaka, Zambia) indicated that the department recorded 203 and 245 RTA victims in September, 2018 and October, 2018 respectively. On average, three RTA victims are admitted every day. While the physical consequences of these RTAs are apparent in soft tissue injuries and bone fractures, psychological consequences and their subsequent effects on neurocognitive functioning are not fully understood. Less attention has been paid to the psychological consequences and neurocognitive consequences of the RTAs in Zambia. Patients are usually left in a vulnerable state after an accident.

Traditionally, general practitioner and physicians practicing trauma medicine tend to pay little attention to a patient's emotional and psychological perspective [4]. Medical ethics has always emphasized that surgical care should include collaboration between surgical care and mental healthcare. Therefore, a patient should be evaluated from both physical and psychosocial perspective. Poor documentation due to low awareness of posttraumatic psychological disorders and subsequent neurocognitive impairment among the surgeons has been observed [5]. While many literatures from other parts of the world have addressed issue of neurocognitive deficits implicated in road traffic accidents and other neurocognitive disorders, such information is unavailable in Sub-Saharan Africa [6-7].

Involvement in RTAs may put individuals at increased risk for a wide range of psychiatric disorders that have significant public health issues and the RTA even itself can trigger existing psychiatric disorder [8-12]. Road traffic crashes have a profound psychological impact on survivors. A large proportion of the RTA victims experience acute and long-term mental conditions. These conditions include post-traumatic stress disorder (PTSD), major depressive disorder and anxiety disorders [13-16]. Prevalence of PTSD following road traffic crashes ranges from $6 \%$ to $45 \%$ and it remains one of the most common consequences of road traffic incidents [17]. Additional responses include grief, panic and bereavement. Mental health support can mitigate many of these conditions and help prevent psychological distress from becoming a disability that interferes with re-integration into work and social life.

Some studies have reported that PTSD is commonly comorbid with substance abuse. A prevalence of between 30 to $50 \%$ among samples of individuals with PTSD has been reported [18]. One explanation for this high prevalence of substance abuse is the self-medication hypothesis, which posits that individuals with PTSD, as well as other mental health problems, may utilise substances in an effort to cope with debilitating and chronic symptoms [18].

The mental health disorders and the traumatic brain injury (TBI) associated with RTA can have an adverse effect on the neurocognitive functioning of the survivor. One study that was aimed at comparing the health status and quality of life between patients with whiplash and other injuries, the psycho-cognitive sequelae stood at $32.7 \%, 27.5 \%$ and $10.7 \%$ for severe TBI, mild TBI and other injuries respectively [19]. There are three cognitive changes that are found in people with trauma and they include: impaired memory, concentration difficulties and difficulties associated with finishing a task [20].

Three published studies have prospectively assessed for cognitive deficits. These have implicated verbal memory, sustained attention, verbal learning, visuospatial memory and reaction-time proficiency deficits and trends toward poorer cumulative learning and verbal fluency. Trauma has been associated with deficits in the areas of verbal memory and learning, executive functioning, working memory and attention in adults [21].

Although evidence concerning impairment in strategic planning, conceptual flexibility, and set-shifting aspects of executive functioning remain unclear, tangible evidence demonstrates that trauma is associated with inhibitory dysfunction across a number of different measures, suggesting difficulty with inhibiting inappropriate or automatic responses [22]. Such results have been used to support a model of generalized dysfunction in inhibitory control, which could help explain difficulties in regulation of both neuropsychological and emotional processes [23]. It has also been proposed that different psychological and psychiatric comorbidities account for a significant proportion of the cognitive deficits [24-28]. Neuropsychological impairment (on tests of information processing, executive functioning, verbal learning, and motor speed) and clinical symptoms of anxiety were found to predict PTSD severity. In particular, symptoms of depression may also explain certain cognitive deficits in individuals with PTSD. Major depressive disorder is associated with a profile of mild deficits in problem solving, inhibition, sustained attention, attentional switching, and episodic memory, with a particular deficit in visual memory in younger outpatients with PTSD [29]. Thus, it is possible that the neurocognitive deficits observed in studies may simply reflect the established comorbidity of PTSD with depression. 
Studies have also drawn attention to pre-trauma factors that might affect neurocognitive functioning, including attention-deficit/hyperactivity disorder (ADHD) and pre-trauma intelligence estimates, it is possible that unrecognized ADHD comorbidity could contribute to neurocognitive findings reported [30-32]. However, this has rarely been examined. Adult ADHD has been reported to have a profile of cognitive deficits in attention, episodic memory encoding, and executive function, raising the question of whether ADHD could explain some of the neurocognitive findings [33]. Intelligence estimates have robust associations with neurocognitive performance. Therefore, it is possible that limited premorbid intellectual resources may be partially responsible for cognitive deficits in individuals [34].

Consensus regarding the neurocognitive effects of RTAs and the impact of other potential explanatory variables remain elusive due to inconsistencies in the literature. The ability to draw clinically meaningful conclusions from the existing literature is limited by the absence of a quantitative determination of the nature and extent of cognitive deficits in RTA victims based on results from multiple independent studies. Despite the considerable number of studies, especially in western countries, examining neurocognitive deficits associated with RTAs, consensus regarding the pattern and magnitude of these effects remains elusive and some researchers question the link between RTA trauma and cognitive dysfunction [35].

This research was undertaken to find out the neurocognitive deficits among adult road traffic accident victims at the University Teaching Hospital in Lusaka, Zambia.

\section{Methodology}

The study utilized a cross sectional study design (descriptive type). In this study, data was collected from participants aged 18 to 50 years. The participants were assessed using the WHO QOL questionnaire and the international neurobehavioral battery which tests seven domains of cognition. These domains included visual episodic domain, verbal episodic, verbal fluency, speed of information processing, executive functioning, working memory and attention and motor dexterity domains. This study assessed speed of information processing and executive functioning only. Prior to administration of the selected tests from the international neurobehavioral battery, the medical records were used to screen for RTA trauma to ensure that relevant information concerning each participant was obtained.

This study was conducted in Lusaka, Zambia at the University Teaching Hospital (UTH), particularly clinic 3 (orthopedic clinic) and clinic 4 (neurology clinic). The clinics were accessed based on the permission obtained from UTH management. These clinics provide treatment to RTA victims living in Lusaka and outside Lusaka.

The sample size was calculated manually using finite population formula at standard variate of $1.96,95 \%$ confidence levels, standard deviation of the population of 8.0 and acceptable error of \pm 3 . The sample size of 30 participants was recruited in the study taking into account $10 \%$ of patients whose information did not contribute to analysis due to loss of follow ups and inability to understand instructions from the test battery.

Participants were recruited by the nurses at the two clinics. The nurses were also obtaining informed consent from the participants before referring them to the researcher. A total of 30 participants of different age and gender from both urban and rural areas were enrolled.

\section{Results}

The data was analyzed using descriptive and inferential statistics using SPSS version 20.

Descriptive statistics were primarily used to describe demographic data and this has been presented as frequencies and percentages.

Regression analysis was used to evaluate the relationship between variables of interest (Independent variable: RTA and gender; Dependent variable: neurocognitive functioning).

Analysis of variance (ANOVA) was used to determine the effects of RTAs on the quality of life based on neurocognitive deficits.

A total of 30 participants were recruited in this study, 15 females and 15 males. Each gender had a 50\% representation. There was no statistical difference in age between the RTA trauma male participants $(\mathrm{M}=33.00, \mathrm{SD}=6.78)$ and the RTA trauma female participants $(M=32.73, S D=10.62$; $P=0.935)$. Equally, no statistical difference was observed in terms of 
years of education between male participants $(M=10.87, S D=2.20)$ and female participants $(M=9.40, S D=3.56$; $\mathrm{P}=0.186)$. The effects of "normal" age, education, and sex on the neurocognitive test performances were controlled for by using demographically corrected standard scores (T-scores) generated with a previously collected 324 normative sample. Table 1 shows demographics in accordance with gender.

Table 1 Demographics according to gender

\begin{tabular}{|l|c|c|c|c|}
\hline Demographics & Groupings & Male (frequency) & Female (frequency) & Percentage (\%) \\
\hline \multirow{4}{*}{ Age (years) } & $18-25$ & 2 & 5 & 23.3 \\
\cline { 2 - 5 } & $26-30$ & 4 & 1 & 16.7 \\
\cline { 2 - 5 } & $31-35$ & 3 & 3 & 20.0 \\
\cline { 2 - 5 } & $36-40$ & 5 & 1 & 20.0 \\
\cline { 2 - 5 } & $41-45$ & 0 & 3 & 10.0 \\
\cline { 2 - 5 } & $46-50$ & 1 & 2 & 10.0 \\
\hline \multirow{5}{*}{ Level of education (years) } & $5-7$ & 2 & 5 & 23.3 \\
\cline { 2 - 5 } & $8-9$ & 3 & 4 & 23.3 \\
\cline { 2 - 5 } & $10-12$ & 9 & 4 & 43.3 \\
\cline { 2 - 5 } & $13+$ & 1 & 2 & 10.0 \\
\hline \multirow{5}{*}{ RTA status } & Driver & 2 & 0 & 6.7 \\
\cline { 2 - 5 } & Rider/cyclist & 5 & 0 & 16.7 \\
\cline { 2 - 5 } & Passenger & 6 & 8 & 36.7 \\
\cline { 2 - 5 } & Pedestrian & 2 & 7 & 30.0 \\
\hline
\end{tabular}

Figure 1 demonstrates distribution of the RTA victims according to the age group.

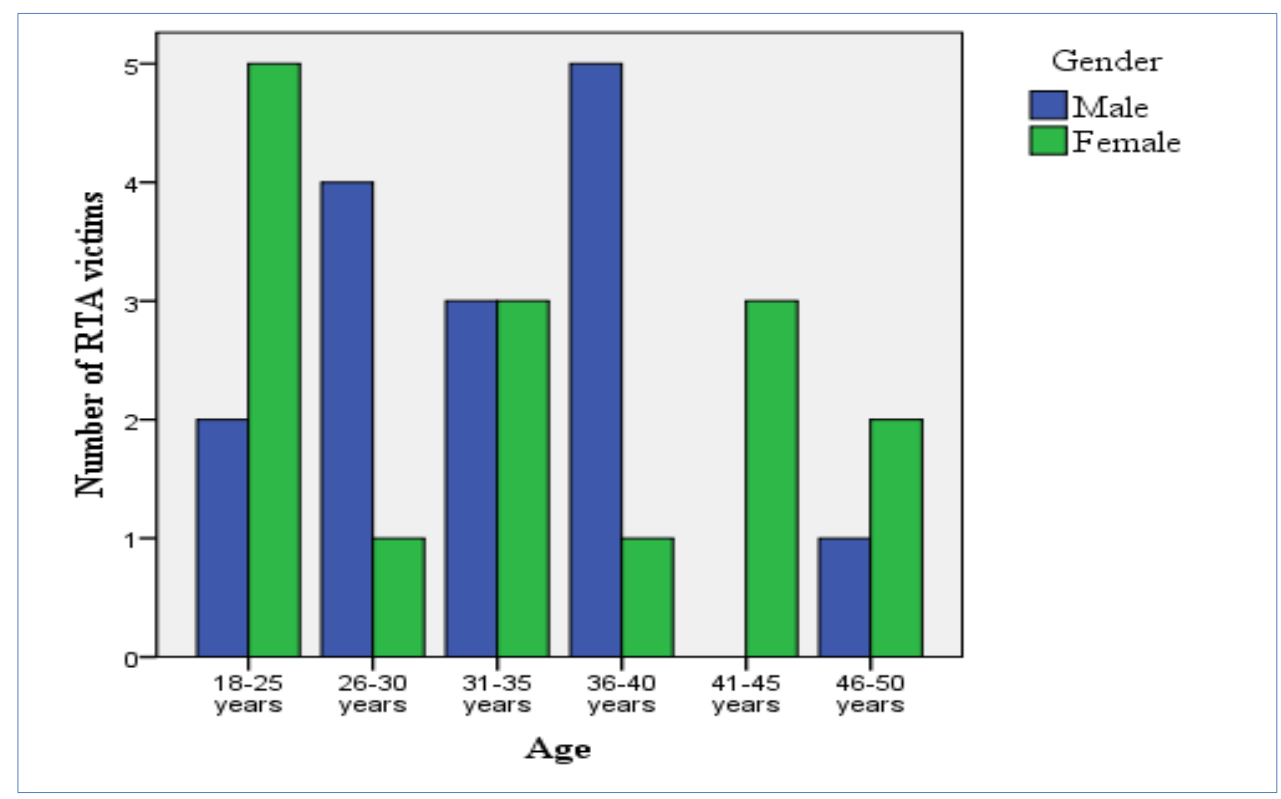

Figure 1 Distribution of RTA victims according to age

Figure 2 shows distribution of RTA victims according to RTA status. 


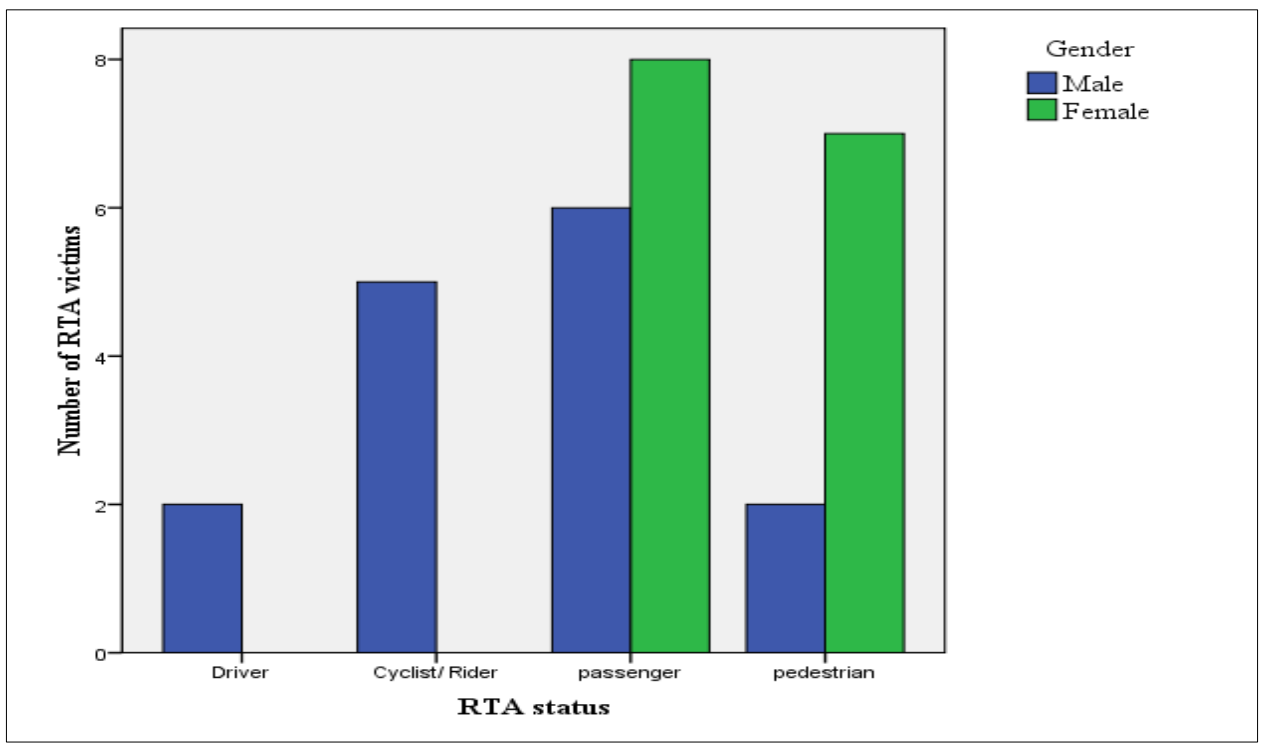

Figure 2 Distribution of RTA victims according to RTA status

Figure 3 emphazises that $10 \%$ of the RTA victims had no executive functioning impairment while $90 \%$ had executive functioning impairment.

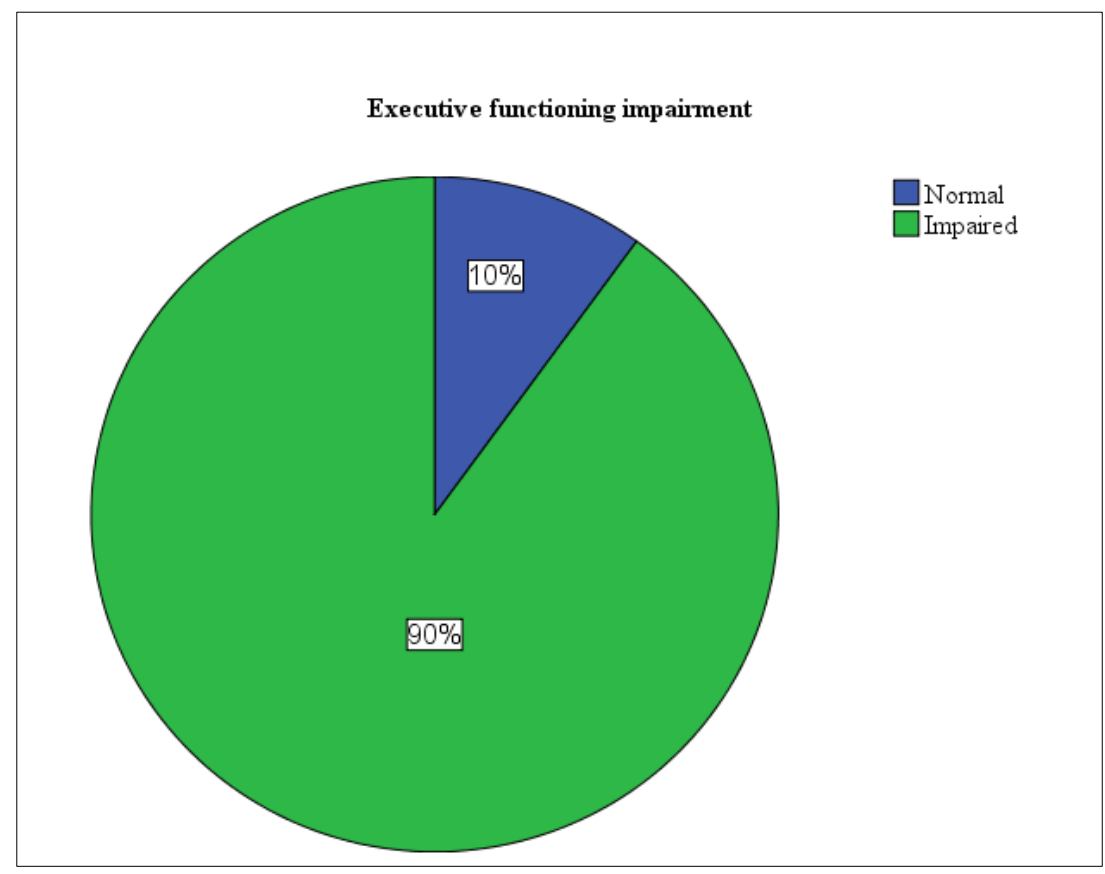

Figure 3 Executive functioning by percentage

Figure 4 shows that basing on the deficit scores, $10 \%$ of the RTA victims were normal with deficit score of 0 while $23 \%$ were mildly impaired with a decicit score of 1 . Approximetly $40 \%$ were mild to moderate impaired with a deficit score of 2 and $27 \%$ were moderately impaired with a deficit score of 3 . There were no moderately impaired and severely impaired with deficit scores of 4 and 5 respectively. 


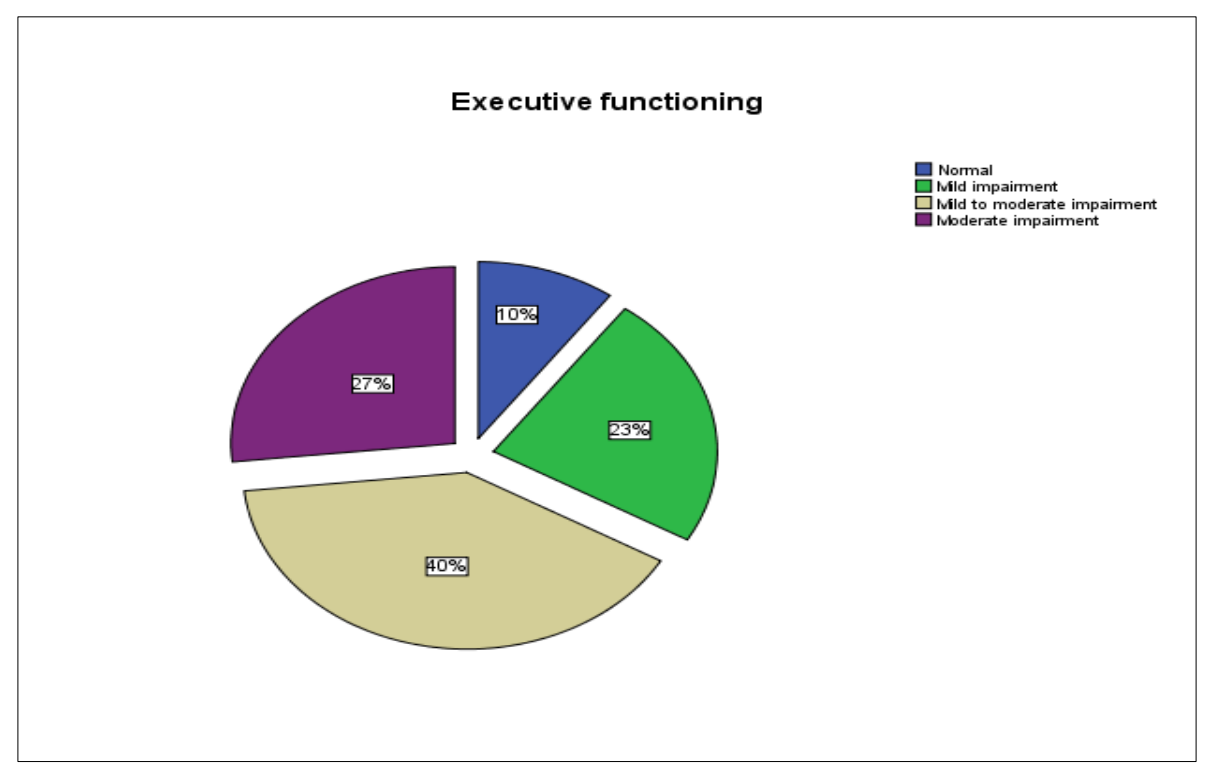

Figure 4 Executive functioning classification by Deficit Scores

Figure 5 demonstrates that Domain Deficit score of $\geq 0.5$ implies impairment in a particular domain, thus 27 RTA victims out of 30 had executive functioning impairment.

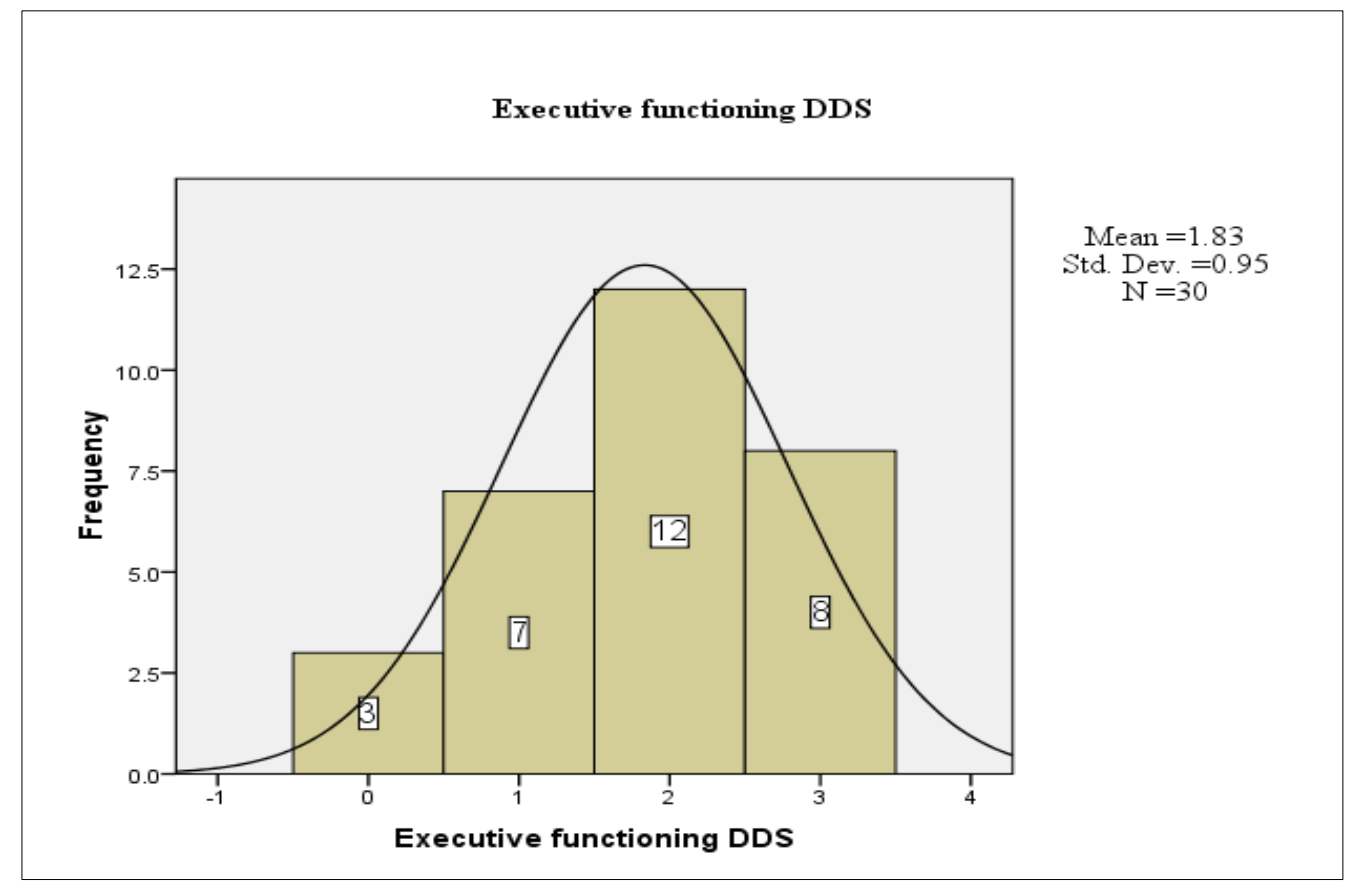

Figure 5 Executive functioning by Domain Deficit Score

Figure 6 highlites that all 30 participants (100\%) had speed of information processing impairment. 


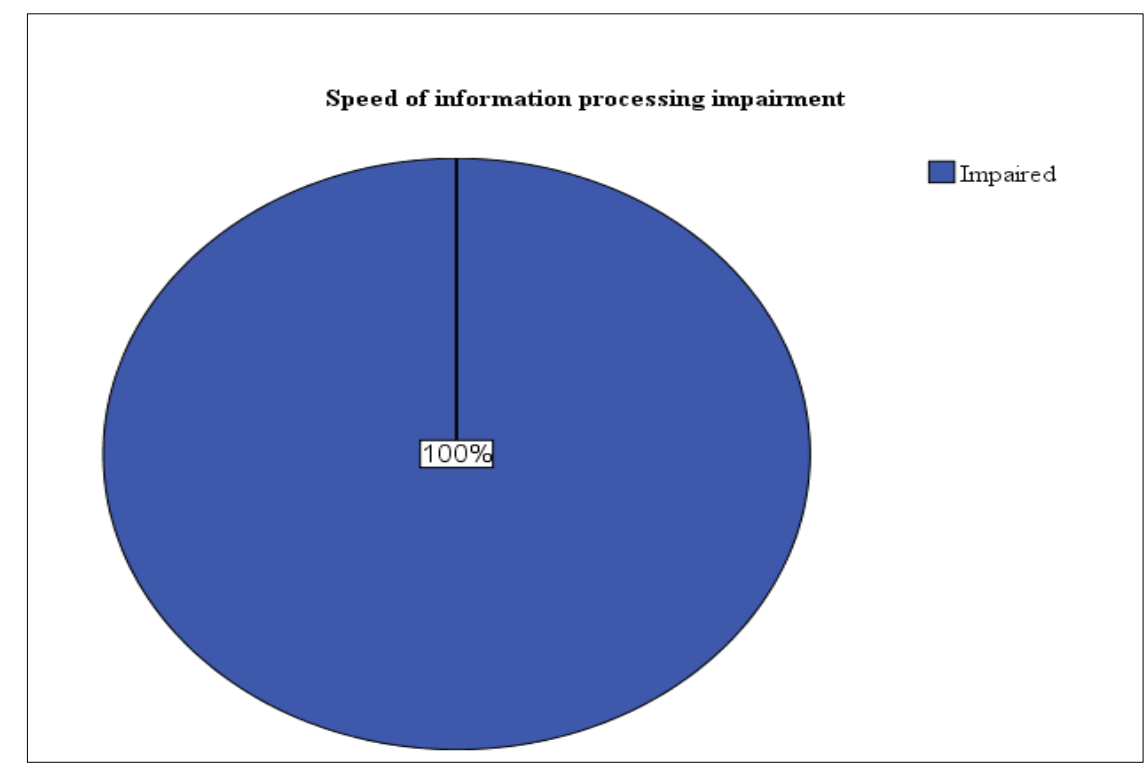

Figure 6 Speed of information processing by percentage

From the Figure 7, there were no normal and mildly impaired RTA victims with deficit scores of 0 and 1 respectively. $3 \%$ of the RTA victims were mild to moderately impaired with deficit score of 2 and 53\% were moderately impaired with a decicit score of 3. $23 \%$ were moderate to severely impaired with a deficit score of 4 and $20 \%$ were severely impaired with a deficit score of 5.

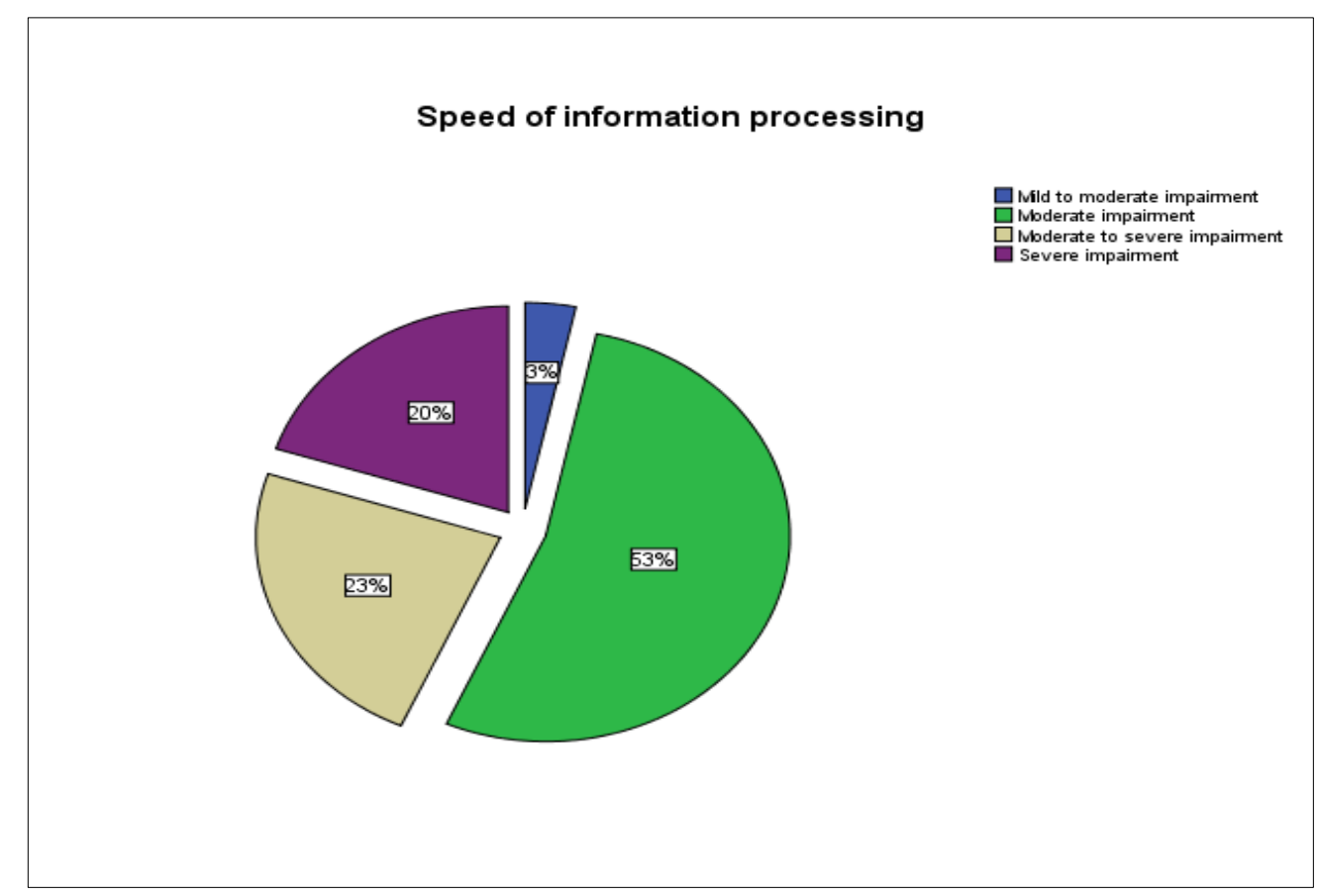

Figure 7 Speed of information processing classification

Figure 8 demonstrated that Domain Deficit score of $\geq 0.5$ implies impairment in a particular domain, thus all RTA victims in the study had speed of information processing impairment. 


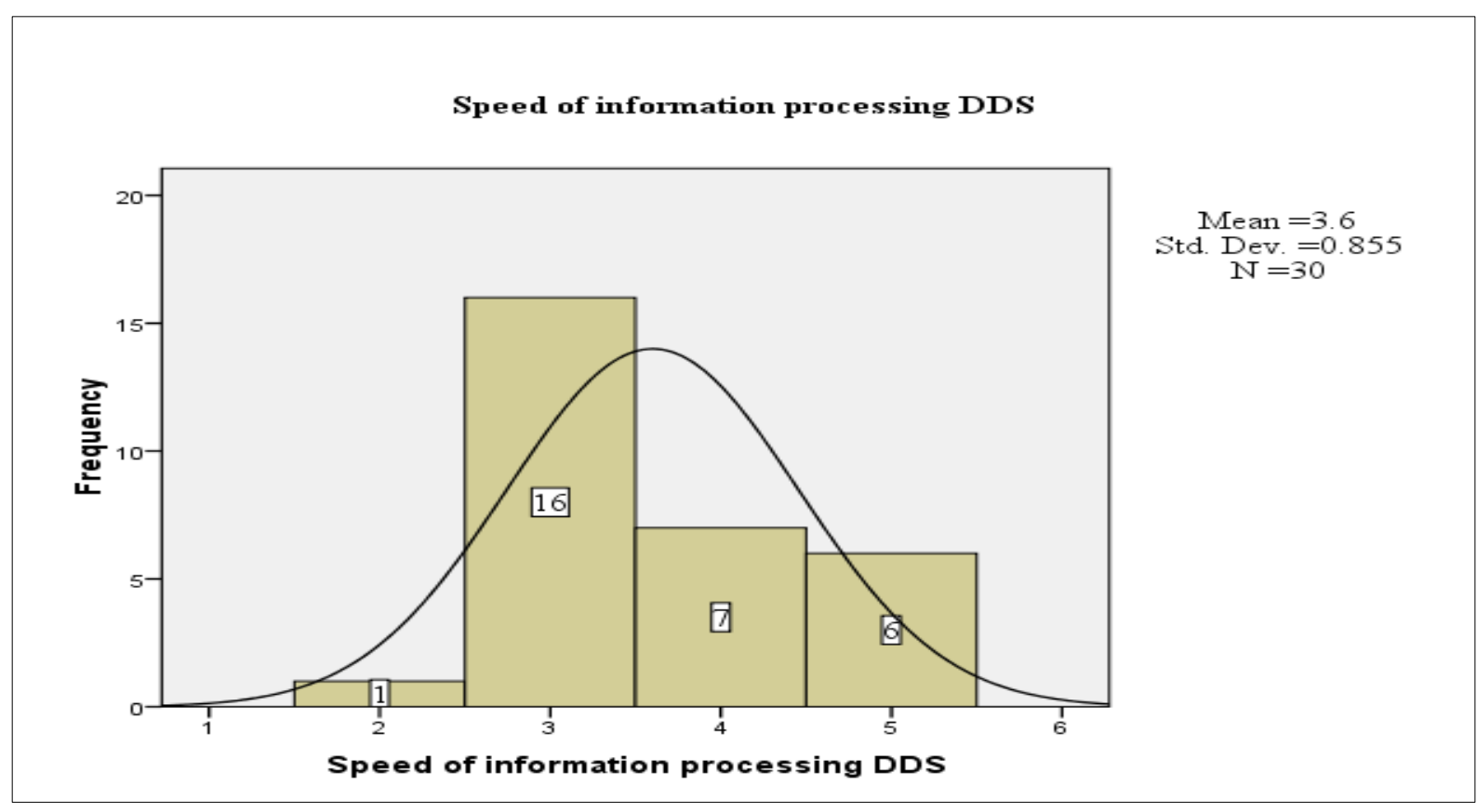

Figure 8 Speed of information processing by Domain Deficit Scores

Apart from gender, the effects of age, education and RTA status on the neuropsychological test performances were also considered. The Table 2 below illustrates the results.

Table 2 Effect of Gender, Age, Education and RTA status on Neuropsychological Tests.

\begin{tabular}{|l|l|l|l|}
\hline Test & Variable & F & P value \\
\hline \multirow{5}{*}{ Modified Wisconsin card sorting test } & Gender & 5.359 & 0.028 \\
\cline { 2 - 4 } & Age & 1.447 & 0.244 \\
\cline { 2 - 4 } & Education level & 0.820 & 0.494 \\
\cline { 2 - 4 } & RTA status & 0.553 & 0.651 \\
\hline \multirow{5}{*}{ Stroop Colour Word Test } & Gender & 5.091 & 0.032 \\
\cline { 2 - 4 } & Age & 0.452 & 0.808 \\
\cline { 2 - 4 } & Education level & 1.835 & 0.166 \\
\cline { 2 - 4 } & RTA status & 0.700 & 0.561 \\
\hline \multirow{5}{*}{ Trail Making Test Part A } & Gender & 4.139 & 0.051 \\
\cline { 2 - 4 } & Age & 0.345 & 0.881 \\
\cline { 2 - 4 } & Education level & 0.376 & 0.771 \\
\cline { 2 - 4 } & RTA status & 0.387 & 0.763 \\
\hline & Gender & 15.750 & 0.000 \\
\cline { 2 - 4 } & Age & 0.375 & 0.861 \\
\cline { 2 - 4 } & Education level & 3.719 & 0.024 \\
\cline { 2 - 4 } & RTA status & 3.960 & 0.019 \\
\hline
\end{tabular}


Table 2 presents the $\mathrm{F}$ values and $\mathrm{P}$ values for the main effects of gender, age, education and RTA status in comparable ANOVAs conducted for each of the selected neurocognitive tests. The results showed that gender had a significant effect on Modified Wisconsin card sorting test, Stroop color word test and Trail making test with $\mathrm{p}<0.05$, but no significant effect on WAIS III symbol search $(p \geq 0.05)$. Age level had no significant effect on the four tests ( $p \geq 0.05)$. Education level and RTA status had a significant effect on the Trail making test part A $(\mathrm{p}<0.05)$ but had no significant effect on the rest of the selected tests. The effects of gender expected were confirmed with male participants scoring higher on 3 of the 4 tests. On the other hand, age had no significant effect on all the four tests. Education level and RTA status had a significant effect on only one test.

Table 3 shows the effect of gender on neuropsychological test performance. The results demonstrated that males had less errors on the MWCST and high scores on the Stroop colour word test, and Trail making test part A while the females scored high only on the WAIS-III symbol search though the difference in performance in this test was insignificant. Males scored highest in three out of four Neuropsychological tests.

Table 3 Mean scores and SD in the Neuropsychological tests according to gender

\begin{tabular}{|l|l|l|}
\hline Test & Male & Female \\
\hline Modified Wisconsin Card Sorting Test & $77.80 \mathrm{SD}=14.55$ & $68.93 \quad \mathrm{SD}=8.58$ \\
\hline Stroop Colour Word Test & $33.13 \mathrm{SD}=4.29$ & $30.47 \mathrm{SD}=6.13$ \\
\hline WAIS-III Symbol Search & $21.13 \mathrm{SD}=3.50$ & $21.80 \mathrm{SD}=5.60$ \\
\hline Trail Making Test Part A & $28.00 \mathrm{SD}=6.19$ & $23.73 \mathrm{SD}=6.68$ \\
\hline
\end{tabular}

Table 4 Mean scores and SD in the Neuropsychological tests according to education level

\begin{tabular}{|l|l|l|l|l|}
\hline Test & Upper primary & $\begin{array}{l}\text { Juniour } \\
\text { secondary }\end{array}$ & $\begin{array}{l}\text { Seniour } \\
\text { secondary }\end{array}$ & Tertiary \\
\hline $\begin{array}{l}\text { Modified Wisconsin Card Sorting } \\
\text { Test }\end{array}$ & $75.00 \mathrm{SD}=9.87$ & $75.86 \mathrm{SD}=15.76$ & $73.08 \mathrm{SD}=13.55$ & $\begin{array}{l}65.00 \\
\mathrm{SD}=4.00\end{array}$ \\
\hline Stroop Colour Word Test & $29.57 \mathrm{SD}=3.65$ & $31.57 \mathrm{SD}=5.50$ & $33.85 \mathrm{SD}=5.87$ & $28.67 \mathrm{SD}=4.62$ \\
\hline WAIS-III Symbol Search & $18.86 \mathrm{SD}=5.55$ & $22.43 \mathrm{SD}=2.30$ & $22.15 \mathrm{SD}=5.19$ & $22.33 \mathrm{SD}=2.31$ \\
\hline Trail Making Test Part A & $20.43 \mathrm{SD}=6.78$ & $24.43 \mathrm{SD}=4.65$ & $28.23 \mathrm{SD}=6.30$ & $31.67 \mathrm{SD}=3.22$ \\
\hline
\end{tabular}

Table 5 Mean scores and SD in the Neuropsychological tests according to age level

\begin{tabular}{|c|c|c|c|c|c|c|}
\hline Test & $\begin{array}{l}18-25 \\
\text { years }\end{array}$ & $\begin{array}{l}26-30 \\
\text { years }\end{array}$ & $\begin{array}{l}31-35 \\
\text { years }\end{array}$ & $\begin{array}{l}36-40 \\
\text { years }\end{array}$ & $\begin{array}{l}41-45 \\
\text { years }\end{array}$ & $\begin{array}{l}46-50 \\
\text { years }\end{array}$ \\
\hline $\begin{array}{l}\text { Modified Wisconsin } \\
\text { Card Sorting Test }\end{array}$ & $\begin{array}{l}70.57 \\
S D=13.49\end{array}$ & $\begin{array}{l}84.60 \\
S D=19.15\end{array}$ & $\begin{array}{l}69.00 \\
S D=6.69\end{array}$ & $\begin{array}{l}73.50 \\
S D=9.61\end{array}$ & $\begin{array}{l}77.67 \\
S D=11.06\end{array}$ & $\begin{array}{l}65.33 \\
S D=4.73\end{array}$ \\
\hline $\begin{array}{l}\text { Stroop Colour Word } \\
\text { Test }\end{array}$ & $\begin{array}{l}33.29 \\
S D=7.02\end{array}$ & $\begin{array}{l}30.40 \\
S D=1.52\end{array}$ & $\begin{array}{l}32.00 \\
S D=6.72\end{array}$ & $\begin{array}{l}33.50 \\
S D=5.13\end{array}$ & $\begin{array}{l}27.67 \\
S D=3.79\end{array}$ & $\begin{array}{l}31.00 \\
\mathrm{SD}=5.00\end{array}$ \\
\hline $\begin{array}{l}\text { WAIS-III Symbol } \\
\text { Search }\end{array}$ & $\begin{array}{l}22.14 \\
\mathrm{SD}=6.15\end{array}$ & $\begin{array}{l}21.40 \\
\mathrm{SD}=3.65 \\
\end{array}$ & $\begin{array}{l}22.17 \\
\mathrm{SD}=2.23\end{array}$ & $\begin{array}{l}23.33 \\
\mathrm{SD}=3.20 \\
\end{array}$ & $\begin{array}{l}18.67 \\
S D=5.69\end{array}$ & $\begin{array}{l}17.67 \\
\mathrm{SD}=7.02 \\
\end{array}$ \\
\hline $\begin{array}{l}\text { Trail Making Test } \\
\text { Part A }\end{array}$ & $\begin{array}{l}24.43 \\
\mathrm{SD}=6.90\end{array}$ & $\begin{array}{l}27.00 \\
S D=4.85\end{array}$ & $\begin{array}{l}29.50 \\
S D=6.16\end{array}$ & $\begin{array}{l}26.17 \\
S D=6.85\end{array}$ & $\begin{array}{l}22.67 \\
S D=6.658\end{array}$ & $\begin{array}{l}22.67 \\
S D=11.02\end{array}$ \\
\hline
\end{tabular}

From the Table 4 it is clear that the effect of years of school on neuropsychological test performance is obvious. In the MWCST, groups showed a trend of reduced errors with lower education. There was an increase in scores with higher 
education in the Trail making test part A. In the Stroop color word test, the senior secondary group scored the highest. The Junior secondary group scored high in the MWCST and WAIS-III symbol search. Each of the four groups was highest in only one of the four neuropsychological tests an indication that performance on the neuropsychological tests was not significantly affected by the number of years in schooling.

Table 5 shows the effect of age level on neuropsychological test performance. The results showed that the 36-40 age group was scoring high in the stroop colour word test and the WAIS-III symbol search while 26-30 and 31-35 age group scored highest in the MWCST and the Trail making part A respectively. However, the results showed that there was no significant effect of age on neuropsychological test performance.

Table 6 illustrates the effect of RTA status on neuropsychological test performance. Riders/ cyclists scored highest in the MWCST and the stroop colour word test while drivers scored highest in the WAIS-III symbol search and Trail making test part A but were least in the MWCST. Passengers were least in the stroop colour word test while pedestrians were least in the WAIS-III symbol search and Trail making test part A. There was a decrease in scores from driver status to pedestrian in the Trail making test part A, however there was no significant effect of RTA status on neurocognitive performance.

Table 6 Mean scores and SD in the Neuropsychological tests according to RTA status

\begin{tabular}{|l|l|l|l|l|}
\hline Test & Driver & Rider/cyclist & Passenger & Pedestrian \\
\hline $\begin{array}{l}\text { Modified Wisconsin Card } \\
\text { Sorting Test }\end{array}$ & $\begin{array}{l}65.50 \\
\mathrm{SD}=.707\end{array}$ & $\begin{array}{l}78.20 \\
\mathrm{SD}=12.76\end{array}$ & $73.14 \mathrm{SD}=15.38$ & $72.78 \mathrm{SD}=8.76$ \\
\hline Stroop Colour Word Test & $33.00 \mathrm{SD}=1.41$ & $34.40 \mathrm{SD}=6.88$ & $30.71 \mathrm{SD}=4.71$ & $31.78 \mathrm{SD}=6.16$ \\
\hline WAIS-III Symbol Search & $22.50 \mathrm{SD}=2.12$ & $21.80 \mathrm{SD}=2.95$ & $22.29 \mathrm{SD}=5.05$ & $19.78 \mathrm{SD}=5.07$ \\
\hline Trail Making Test Part A & $33.00 \mathrm{SD}=1.41$ & $29.40 \mathrm{SD}=6.50$ & $27.36 \mathrm{SD}=4.24$ & $20.00 \mathrm{SD}=6.96$ \\
\hline
\end{tabular}

From the four tables, 3, 4, 5 and 6, it is evident that while there were differences in neuropsychological test performance according to gender, there was no significant difference in performance according to age, education level and RTA status.

Table 7 shows that there was no significant statistical difference in executive functioning $(\mathrm{F}=0.85 ; \mathrm{P}=0.36)$ and speed of information processing $(\mathrm{F}=0.98 ; \mathrm{P}=0.33)$ according to gender.

Table 7 T-scores based results comparing RTA trauma males and RTA trauma females on ability domains

\begin{tabular}{|l|l|l|l|l|}
\hline Ability domains & Males mean (SD) & Females mean (SD) & $\boldsymbol{F}$ & $\boldsymbol{P}$-value \\
\hline $\begin{array}{l}\text { Executive } \\
\text { functioning }\end{array}$ & $\begin{array}{l}33.53 \\
(\mathrm{SD}=3.96)\end{array}$ & $\begin{array}{l}31.83 \\
(\mathrm{SD}=5.94)\end{array}$ & 0.85 & 0.36 \\
\hline $\begin{array}{l}\text { Speed } \\
\text { information } \\
\text { processing }\end{array}$ & $\begin{array}{l}24.57 \\
(\mathrm{SD}=4.27)\end{array}$ & $\begin{array}{l}22.77 \\
(\mathrm{SD}=5.58)\end{array}$ & 0.98 & 0.33 \\
\hline
\end{tabular}

The World Health Organization Quality of Life (WHOQOL) classification has five (5) scale points namely; very poor, poor, neither poor nor good, good, and very good [36]. Six (6) out of thirty (30) were classified under very poor quality of life, nineteen (19) were classified under poor quality of life and five (5) were classified under neither poor nor good. Figure 9 shows that there was no distribution under good and very good quality of life category. Pearson Chi-Square Asymp. Sig. (2-sided) of .512 indicates that there was no statistical significance between gender and WHOQOL classification. 


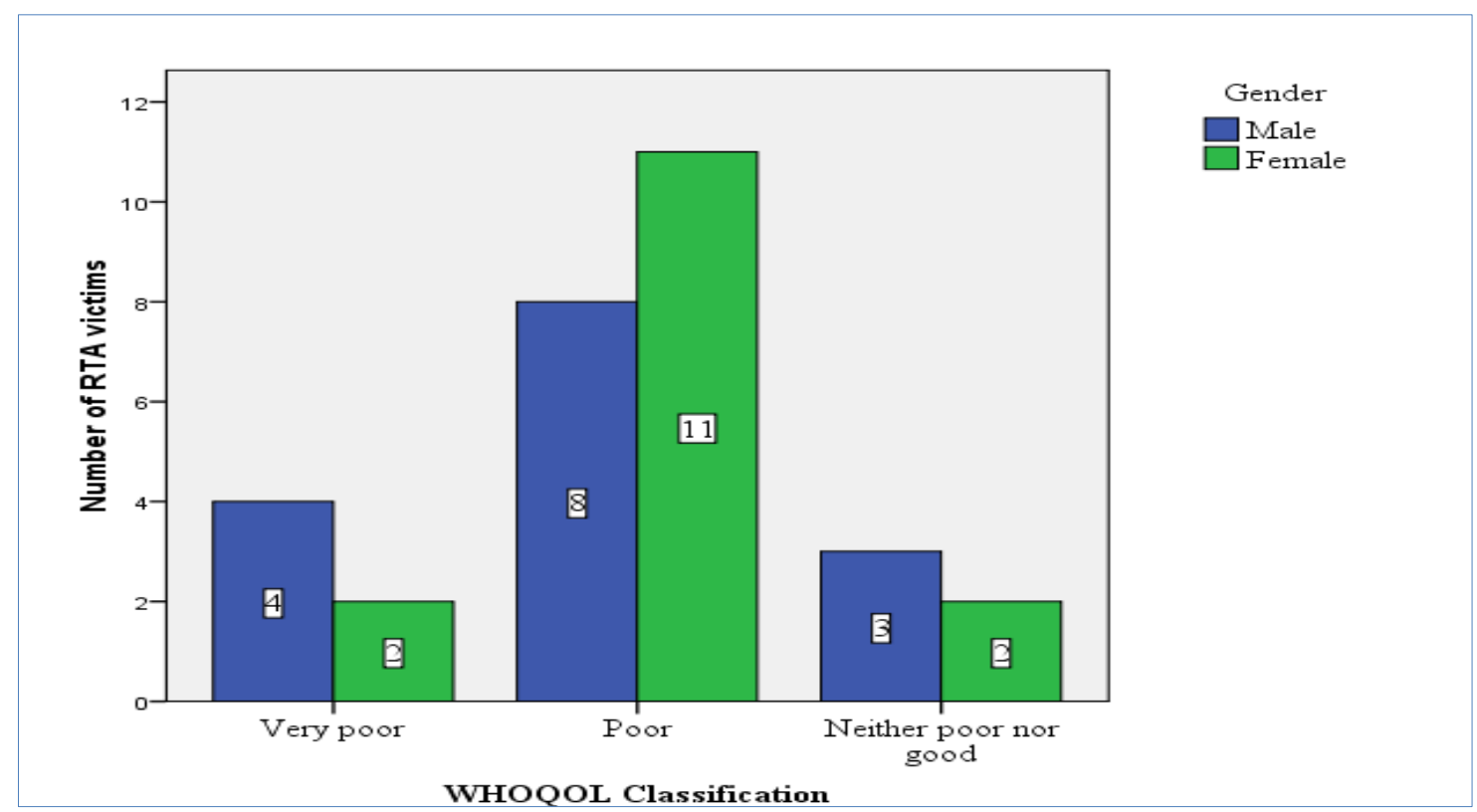

Figure 9 Distribution of RTA victims according to WHOQOL classification

Table 8 summarizes that there was no statistical significance between neurocognitive functioning and physical domain, social domain and general health $(\mathrm{P}>0.05)$. On the other hand, there was statistical significance between neurocognitive functioning and psychological domain $(\mathrm{F}=7.560 ; \mathrm{P}=0.010)$. Statistical significance also existed between neurocognitive functioning and environmental domain ( $\mathrm{F}=6.146 ; \mathrm{P}=0.019)$.

Table 8 RTAs effect on QOL domains based on T-scores mean of executive functioning and speed of information processing (neurocognitive functioning)

\begin{tabular}{|l|l|l|}
\hline QOL domain & F & P value \\
\hline Physical & 0.788 & 0.382 \\
\hline Psychological & 7.560 & 0.010 \\
\hline Social & 0.384 & 0.541 \\
\hline Environmental & 6.146 & 0.019 \\
\hline General health & 3.335 & 0.078 \\
\hline
\end{tabular}

Figure 10 illustrates the distribution of RTA victims according to Executive functioning and WHOQOL classification. Pearson Chi-Square Asymp. Sig. (2-sided) of .360 indicates that there is no statistical significance between executive functioning and WHOQOL classification.

Table 9 Effects of speed of information processing, Executive functioning and neurocognitive functioning on Quality of Life

\begin{tabular}{|l|l|l|}
\hline Independent variable & F & P value \\
\hline Speed of information processing & 3.185 & 0.040 \\
\hline Executive functioning & 1.371 & 0.274 \\
\hline Neurocognitive functioning by Global Deficit Score (GDS) & 4.531 & 0.005 \\
\hline
\end{tabular}




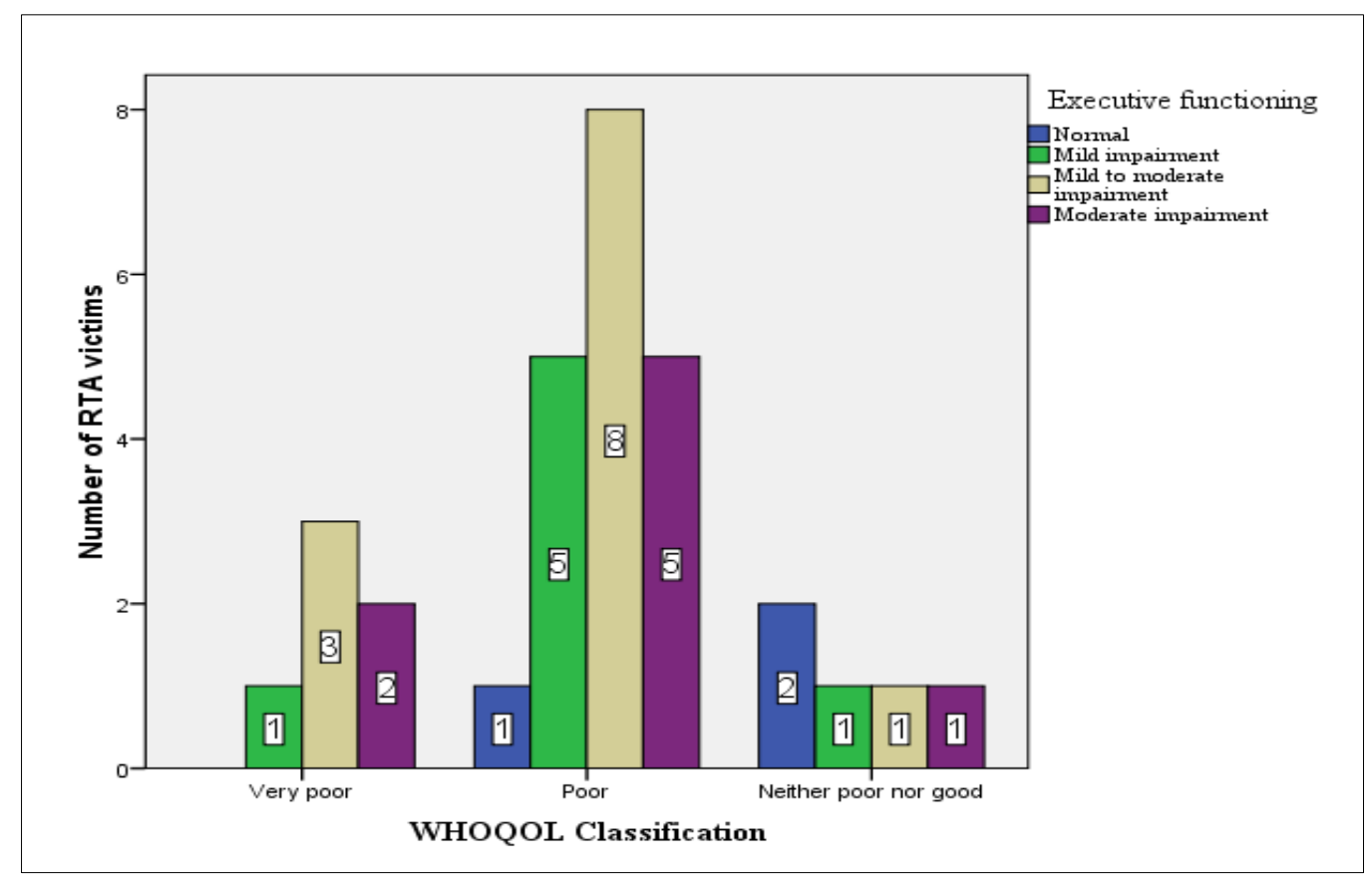

Figure 10 Distribution of RTA victims according to Executive functioning and WHOQOL classification

Figure 11 compares RTA victims in accordance with the speed of information processing and WHOQOL classification. Pearson Chi-Square Asymp. Sig. (2-sided) of .140 indicates that there is no statistical significance between speed of information processing and WHOQOL classification.



Figure 11 Distribution of RTA victims according to Speed of information processing and WHOQOL classification

From the Table 9, it is clear that statistical significance existed between speed of information processing and quality of life $(\mathrm{F}=3.185 ; \mathrm{P}=0.040)$. No statistical significance existed between executive functioning and quality of life $(\mathrm{F}=1.371$; $\mathrm{P}=0.274)$. Overall, statistical significance existed between neurocognitive functioning and quality of life $(\mathrm{F}=4.531 ; \mathrm{P}=$ 0.005). This implies that impaired neurocognitive functioning has an adverse effect on the quality of life. 


\section{Discussion}

According to World Health Organisation (WHO), people who survive road crashes may be likely to experience significant trauma resulting in a range of potential health conditions leading to short term or permanent disabilities [37]. Musculoskeletal, spinal cord injuries (SCI) and traumatic brain injury are common in RTA victims. Depending on the size and locations of damage, this can cause significant physical, cognitive and behavioural impairments. In consensus with the observation by the WHO, the finding of the study revealed neurocognitive impairment in the two domains that were investigated [37]. 90\% of the RTA victims had impairments in the executive functioning domain while 100\% (all the participants in the study) had impairments in speed of information processing.

Hour et al (2014) found that the psychocognitive sequelae stood at $32.7 \%, 27.5 \%$ and $10.7 \%$ for severe TBI, mild TBI and other injuries respectively [19]. The findings reported in the study mentioned above stated that for other injuries it appears to be smaller percentage than what our study has revealed. Our study only focused on two domains but the study by Hour et al (2014) focused on several domains. In most cases, studies have typically only assessed a circumscribed range of neurocognitive functions, often with varying tests, which can lead to ambiguity in determining the effects of a traumatic event such as RTA on neurocognitive functioning.

This study has indeed revealed that involvement in a road traffic accident can alter the cognitive functioning of the victim. In consensus, Gale et al (2008) posit that trauma has been associated with deficits in the areas of verbal memory and learning, executive functioning, working memory and attention in adults [21]. Advances in the neuroscience of trauma has implicated a larger pathophysiological role for the prefrontal cortex which is responsible for additional difficulties in executive functioning (Aupperle et al, 2012) and speed of information processing (Cohen et al, 2013) [23, 38]. Executive functioning and speed of information processing rely on the integrity of prefrontal cortical networks and efficient connectivity between frontal regions and other large-scale brain networks [39]. The findings above are in tandem with the findings of this study. As much as other domains were not examined, the assessed domains (i.e. executive functioning and speed of information processing) were impairments. Cognitive, social and emotional impairments seen in RTA patients may also be assessed and diagnosed in patients with chemical and non-chemical addiction [40-41].

Study results may mean that adult Zambians who are involved in RTAs are most likely to have problems in decision making, planning, evaluation and monitoring due to impairments in the executive functioning. Another important fact is that the impact of RTAs will slow down the rate at which these individuals process information in the brain due to the impairment in the speed of information processing domain. The implications of the study results are that adult Zambian victims of RTA may require human resource placement and care at work depending on the kind of work involved, some may require rehabilitation and clinicians will have to be vigilant as to when to start holistic treatment targeting the physical, neuropsychological and emotional aspects of the victims so as to protect the central nervous system from further damage in order to promote continued quality of life and productivity over the lifespan.

According to Olff et al (2007), there are several findings that suggest that women have more negative self-schemas and world-schemas which may make them more prone to neurocognitive deficits than men [42]. This is supported by Dai et al (2016) and Forman (2015) who posit that the gender differences are largely attributed to gender difference in coping strategies when facing trauma, as well as gender difference in interpretation of trauma [43-44]. It has been wellestablished that female subjects interpret trauma more negatively than their male counterparts. Thus, high vulnerability to stress may entail adverse effect on neurocognitive functioning among women. The same as people suffering RTAs consequences, people with some comorbid psychiatric disorders (e.g., bipolar disorder, depressive disorder or schizophrenia) may also be exposed to stress and its consequences more than general population [12,14-15, 24-25, 45].

In this study, male participants performed better than female in three out of the four neuropsychological tests. However, the data obtained from testing the participants using the neuropsychological test battery revealed no significant difference in the level of neurocognitive impairment between male and female who are involved in RTAs. This disconfirmed the hypothesis that female participants would score lower on the neuropsychological tests than the male participants of the same age and educational level. This finding is different from what several authors have suggested that gender may, to a certain extent, have some confounding effects regarding traffic accident health and functional consequences.

The findings of this study were at odds with those that were previously reported which suggested significant gender differences in neurocognitive functioning owing to RTA trauma [42]. Possible reasons for this disparity could be that previous studies did not utilize Zambian norms, and/or did employ a comprehensive test battery. Most studies have revealed that women's performance on neuropsychological test is usually low but in the current study the scores for 
women were not significantly different from those of men. This could be attributed to the fact that the selection of the sample in the current study only included males and females with no statistical difference in terms of age and level of education. In addition, the effects of age and level of education were counteracted at the point of conversion of raw scores to T scores.

The participants' quality of life in this study were classified according to the five-point scale ("very poor", "poor", "neither poor nor good", "good" and "very good"). Majority of RTA victims were classified as having a poor quality of life. This finding is in tandem with Mayou et al (1993) whose study revealed that not only were post-traumatic symptoms common among RTA survivors but they were associated with very considerably impaired quality of life, impairment which was often prolonged and disabling [46].

The study found statistical significance between neurocognitive functioning and psychological domain of quality of life. According to Mayou (2002), a large proportion of crash survivors' experience acute and long-term psychological conditions [13]. These conditions are post-traumatic stress disorder (PTSD), major depressive disorder and anxiety disorders. This was in tandem with Zungu et al (2011) who in their study outlined the psychological mechanisms such as depression, hostility and poor coping as the most prominent among trauma victims [20]. All these psychological mechanisms have been linked to adverse health effects.

There was also statistical difference between neurocognitive functioning and the environmental domain of quality of life. The psychological domain and the environmental domain were affected mainly because RTA victims did not receive any form of intervention in these areas. Domains which were not affected (i.e. social, physical and general health) received some form of intervention. RTA victims had strong social relationships and they were receiving medical attention with regards to their physical wellbeing and general health.

Trauma may increase negative health perceptions and illness behaviour. For example, Richards et al (2000) have suggested that avoidance of thinking about a trauma, and mislabeling of the autonomic and emotional consequences of such avoidance (in addition to actual biological changes and secondary gain), both of which are associated with poor health and poor quality of life [47].

Some RTA victims may achieve excellent recovery and return to their original level of functioning rapidly. However, many survivors may require extended support to re-integrate into work and home life. Supportive services range from home modification, organization of caregivers and access to assistive products or medical supplies, to vehicle adaptation, employment counselling and emotional support. Unfortunately, despite the increasing needs for multidisciplinary rehabilitation services, these services are non-existent or extremely limited in many parts of the world [48].

\section{Conclusion}

The results obtained from this study indicates that $90 \%$ of RTA victims had impairment in executive functioning while $100 \%$ (all the participants in the study) had impairment in speed of information processing. The severity of impairment ranged from mild to moderate for executive functioning and from mild to severe for speed of information processing. Majority of the RTA victims were categorized as mild to moderately impaired under executive functioning domain. Under speed of information processing domain, majority of the RTA victims were categorized as moderately impaired. The results further revealed that there were gender differences related to neurocognitive deficits in adult RTA victims. The results obtained from the WHOQOL indicated that RTA compromises the quality of life of survivors. The quality of life was classified as "very poor", "poor" and "neither poor nor good" with majority of them falling under "poor". There was no "good" and "very good" quality of life classification.

\section{Recommendations}

Based on the study findings, the following recommendations have been made:

- There is a significant need for neuropsychologists and other health practitioners to conduct more studies on the link between RTAs and neurocognitive functioning in Zambia, preferably focusing on all the domains. So far not much has been done in this area;

- Psychologists and neuropsychologists have to modify neuropsychological tests to accommodate and utilize the use of local languages; 
- There is a gap that should be addressed by policy makers locally (at the ministry of health), to put in place policies that ensure collaboration between surgical care and mental health care;

- There is a need for policy makers at the ministry of health to formulate policies and guidelines that ensure liaison psychiatric services;

- There is a significant need for medical personnel and allied health workers to holistically screen RTA victims in order to ensure early intervention and management of their physical, neuropsychological and emotional needs (holistic comprehensive rehabilitation);

- Adult Zambian victims of RTA may require human resource placement and care at work depending on the nature of work. There is need for work adjustment and supported employment;

- The road traffic agency should ensure that traffic signs are properly marked and placed. In addition, there is need to improve pavements, especially along busy roads, in order to protect vulnerable road users such as pedestrians.

\section{Compliance with ethical standards}

\section{Acknowledgments}

We thank all our patients who participated in the study and the administration and medical team of the University Teaching Hospital (UTH) for their help and support.

\section{Disclosure of conflict of interest}

The authors declare that there is no conflict of interest.

\section{Statement of ethical approval}

This research was approved by biomedical research ethics committee "ERES Converge" (ref. \# 2019-Mar-005). The permission to conduct this research was also granted by the administration (the Head Clinical Care) of the University Teaching Hospital (UTH) on the $27^{\text {th }}$ May, 2019.

\section{Statement of informed consent}

Informed consent was obtained from all individual participants included in the study.

\section{References}

[1] Marshall S J. Developing countries face double burden of disease. Bulletin of the World Health Organization, 2004; 82:556-556.

[2] Nwadiaro H C. Road Traffic Accident in Nigeria: a major catastrophe. Journal of Medicine in the Tropics, 2004; 6(2):1-7.

[3] GRZ. Ministerial statement to parliament on measures to reduce road traffic accidents in Zambia. Ministry of Transport and Communications - Zambia. 2017.

[4] Phiri C, Tsarkov A, Petlovanyi P and Lingenda G. Factors Contributing To Oral Diseases and Treatment Needs amongst Mental Patients at Chainama Hills College Hospital, Lusaka, Zambia. Imperial Journal of Interdisciplinary Research (IJIR), 2017; 3(11):495-504.

[5] Bisson J I, Shepherd J P and Dhutia M. Psychological sequelae of facial trauma. Journal of Trauma and Acute Care Surgery, 1997; 43(3):496-500.

[6] Tsarkov A and Petlovanyi P Neuropsychiatric aspects of a common problem: stroke. European Journal of Medical and Health Sciences (EJMED), 2019; 1(3):1-6.

[7] Seethalakshmi R, Dhavale H S, Gawande S and Dewan M. Psychiatric morbidity following motor vehicle crashes: a pilot study from India. Journal of Psychiatric Practice $\AA, 2006 ; 12(6): 415-418$.

[8] Kovacevic J, Miskulin M, Degmecic D, Vcev A, Leovic D, Sisljagic V and Miskulin I. Predictors of mental health outcomes in road traffic accident survivors. Journal of clinical medicine, 2020; 9(2):309.

[9] Msoni P C, Tsarkov A and Petlovanyi P. Induced Delusional Disorder: A Case Report. 
[10] Tsarkov A, Patrick M and Petro P. Uncommon presentation: Folie à deux (Case study). World Journal of Advanced Research and Reviews (WJARR), 2020; 6:43-49.

[11] Rawal N, Thapa P and Bista Y. A study of psychiatric consequences following road traffic accidents. Medical Journal of Shree Birendra Hospital, 2010; 9(2):pp.1-7.

[12] Petlovanyi P and Tsarkov A. Child Schizophrenia: Theory and Practice. European Journal of Medical and Health Sciences (EJMED), 2020; 2(1):1-5.

[13] Mayou R and Bryant B. Outcome 3 years after a road traffic accident. Psychological medicine, 2002; 32(4):671675.

[14] Tsarkov A and Petlovanyi P. Depressive Disorder in Child Psychiatric Practice: A Case Report. The Health Press (Zambia), 2017; 9-16.

[15] Tsarkov A and Petlovanyi P. Depressive Disorder in Child Psychiatric Practice: A.

[16] Mayou R, Bryant B and Ehlers A. Prediction of psychological outcomes one year after a motor vehicle accident. American Journal of Psychiatry, 2001; 158(8):1231-1238.

[17] Heron-Delaney M, Kenardy J, Charlton E and Matsuoka Y. A systematic review of predictors of posttraumatic stress disorder (PTSD) for adult road traffic crash survivors. Injury, 2013; 44(11):1413-1422.

[18] Brady K T, Back S E and Coffey S F. Substance abuse and posttraumatic stress disorder. Current directions in psychological science, 2004; 13(5):206-209.

[19] Hours M, Khati I, Charnay P, Chossegros L, Tardy H, Tournier C and Laumon B. One year after mild injury: comparison of health status and quality of life between patients with whiplash versus other injuries. The Journal of rheumatology, 2014; 41(3):528-538.

[20] Zungu L I Prevalence of post-traumatic stress disorder in the South African mining industry and outcomes of liability claims submitted to Rand Mutual Assurance Company. Occupational health southern Africa, 2013; 19(2), 22-26.

[21] Gale C R, Deary I J, Boyle S H, Barefoot J, Mortensen L H and Batty G D Cognitive ability in early adulthood and risk of 5 specific psychiatric disorders in middle age: the Vietnam experience study. Archives of general psychiatry, 2008; 65(12):1410-1418.

[22] Twamley E W, Allard C B, Thorp S R, Norman S B, Hami Cissell S, Hughes Berardi K, Grimes E M and Stein M B. Cognitive impairment and functioning in PTSD related to intimate partner violence. J Int Neuropsychol Soc., 2009; 15(6):879-87.

[23] Aupperle R L, Melrose A J, Stein M B and Paulus M P. Executive function and PTSD: Disengaging from trauma. Neuropharmacology, 2012; 62(2):686-694.

[24] Tsarkov A and Petlovanyi P. Bipolar Disorder in Child Psychiatric Practice: A Case Report. Medical Journal of Zambia, 43(1), 41-46.

[25] Tsarkov A and Petlovanyi P. Bipolar disorder in child psychiatric practice. 2016.

[26] Castaneda A E, Tuulio-Henriksson A, Marttunen M, Suvisaari J and Lönnqvist J. A review on cognitive impairments in depressive and anxiety disorders with a focus on young adults. Journal of affective disorders, 2008; 106(1-2): 1-27.

[27] Tsarkov A and Petlovanyi P. Use of pramipexole in neuropsychiatry. World Journal of Advanced Research and Reviews (WJARR), 2020; 7(2):82-88.

[28] Trivedi J K. Cognitive deficits in psychiatric disorders: Current status. Indian journal of psychiatry, 2006; 48(1): 10.

[29] Olff M., Polak A R, Witteveen A B and Denys D. Executive function in posttraumatic stress disorder (PTSD) and the influence of comorbid depression. Neurobiology of learning and memory, 2014; 112:114-121.

[30] Tsarkov A and Petlovanyi P. Omega-3 Fatty Acids as an Alternative Treatment for Children with Attention Deficit Hyperactivity Disorder. Imperial Journal of Interdisciplinary Research (IJIR), 2017; 3(2):1378-1380.

[31] Harrington K M, Miller M W, Wolf E J, Reardon A F, Ryabchenko K A and Ofrat S. Attention-deficit/hyperactivity disorder comorbidity in a sample of veterans with posttraumatic stress disorder. Comprehensive Psychiatry, 2012; 53(6):679-690. 
[32] Petlovanyi P and Tsarkov A. Practical guide and some recommendations for the diagnosis and management of Attention deficit hyperactivity disorder (ADHD). World Journal of Advanced Research and Reviews (WJARR), 2020; 6(3):257-261.

[33] Hervey A S, Epstein J N and Curry J F Neuropsychology of adults with attention-deficit/hyperactivity disorder: a meta-analytic review. Neuropsychology, 2004; 18(3):485.

[34] Gilbertson M W, Paulus L A, Williston S K, Gurvits T V, Lasko N B, Pitman R K and Orr S P. Neurocognitive function in monozygotic twins discordant for combat exposure: relationship to posttraumatic stress disorder. Journal of abnormal psychology, 2006; 115(3):484.

[35] Demakis G J, Gervais R O and Rohling M L The effect of failure on cognitive and psychological symptom validity tests in litigants with symptoms of post-traumatic stress disorder. The Clinical Neuropsychologist, 2008; 22(5): 879-895.

[36] WHOQOL Group. The World Health Organization quality of life assessment (WHOQOL): position paper from the World Health Organization. Social science \& medicine, 1995; 41(10):1403-1409.

[37] World Health Organization. Global status report on road safety 2015. World Health Organization. 2015

[38] Cohen B E, Neylan T C, Yaffe K, Samuelson K W, Li Y and Barnes D E. Posttraumatic stress disorder and cognitive function: findings from the mind your heart study. The Journal of clinical psychiatry, 2013; 74(11).

[39] Bressler S L and Menon V. Large-scale brain networks in cognition: emerging methods and principles. Trends in cognitive sciences, 2010; 14(6):277-290.

[40] Tsarkov A and Petlovanyi P. Pathological Gambling: The Old Problem of the Modern World. Imperial Journal of Interdisciplinary Research (IJIR), 2017; 3(8):216-221.

[41] Ramey T and Regier P S Cognitive impairment in substance use disorders. CNS spectrums, 2019; 24(1):102-113.

[42] Olff M, Langeland W, Draijer N and Gersons B P Gender differences in posttraumatic stress disorder. Psychological bulletin, 2007; 133(2):183.

[43] Dai W, Wang J, Kaminga A C, Chen L, Tan H, Lai Z and Liu A. Predictors of recovery from post-traumatic stress disorder after the dongting lake flood in China: a 13-14 year follow-up study. BMC psychiatry, 2016;16(1):1-9.

[44] Forman J L, Lopez-Valdes F J, Duprey S, Bose D, De Dios E D P, Subit D and Segui-Gomez M. The tolerance of the human body to automobile collision impact-a systematic review of injury biomechanics research, 1990-2009. Accident Analysis \& Prevention, 2015; 80:7-17.

[45] Tsarkov A and Petlovanyi P. The Role of Lamotrigine in the Treatment of Bipolar Depression. Imperial Journal of Interdisciplinary Research (IJIR), 2017; 3(8):131-134.

[46] Mayou R, Bryant B and Duthie R. Psychiatric consequences of road traffic accidents. British Medical Journal, 1993; 307(6905):647-651.

[47] Richards J M, Beal W E, Seagal D and Pennebaker J W Effects of disclosure of traumatic events on illness behavior among psychiatric prison inmates. Journal of Abnormal psychology, 2000; 109(1):156.

[48] Hyder A A, Paichadze N, Toroyan T and Peden M M. Monitoring the decade of action for global road safety 20112020: an update. Global public health, 2017; 12(12):1492-1505. 